\title{
Parental response during a febrile seizure in their child and their knowledge on preparedness for a similar recurrence in their child: A study from the Lady Ridgeway Children's Hospital
}

\author{
*Ashan Jayawickrama ${ }^{1}$, H M Udara ${ }^{1}$, Withanage D Duminda ${ }^{1}$, Jayasanka Jayawardhana ${ }^{1}$, Jithangi \\ Wanigasinghe ${ }^{1}$
}

Sri Lanka Journal of Child Health, 2021; 50(2): 280-285

\begin{abstract}
Introduction: Febrile seizures (FS) are the commonest convulsions in children in the 6-60 month age group. They are a cause of great concern and fear for the parents, often resulting in inappropriate management.
\end{abstract}

Objectives: To describe the parental responses during FS and to document the parental knowledge on how to manage a recurrence.

Method: A prospective study was performed on 160 randomly selected parents of children admitted to Lady Ridgeway Children's Hospital with FS over a two year period. A pretested and validated interviewer-administered questionnaire was used to assess the parental immediate responses towards the seizure and knowledge on how to manage the next seizure.

Results: The mean age of the affected children was 2.2 years (SD 1.50). The male: female ratio was $1.53: 1$. The majority (58\%) were admitted with a first FS. The type of FS was simple in $75.6 \%$ and complex in $24.4 \%$. Only $28 \%$ had ongoing seizures during the admission. The negative parental responses towards the seizure were becoming frightened in 144 (90\%), confused about what to do in $76(47.5 \%)$, and attempting to open the mouth by force in 37 (23\%). Positive responses included keeping the child in a safe posture in $76(47.5 \%)$, shouting for help in $114(71.3 \%)$ and feeling empowered to manage the seizure appropriately in

${ }^{1}$ Department of Paediatrics, Faculty of Medicine, University of Colombo, Sri Lanka

*Correspondence: ashanjayawickrama@gmail.com

https://orcid.org/0000-0003-0192-7265

(Received on 20 May 2020: Accepted after revision on 19 June 2020)

The authors declare that there are no conflicts of interest

Personal funding was used for the project.

Open Access Article published under the Creative Commons Attribution CC-BY (c) (i) License
$66(41.3 \%)$. Only 35 (29\%) had scored adequately on knowledge of how to act during a seizure based on advice given after admission. Inappropriate actions performed included vigorous wet sponging in $122(76.3 \%)$, restraining the clonic movements in $102(63.7 \%)$ and inserting an object to mouth in $131(81.9 \%)$.

Conclusions: This study revealed both negative and positive parental responses when their child experienced a febrile seizure. These responses led them to perform inappropriate first aid measures.

DOI: http://dx.doi.org/10.4038/sljch.v50i2.9572

(Keywords: Febrile seizures, parental knowledge, emergency management)

\section{Introduction}

A febrile seizure (FS) is defined as "a seizure associated with fever that occurs in children aged over one month with no history of previous neonatal or unprovoked afebrile convulsions with no infection involving the central nervous system (CNS), and or no identifiable causes such as electrolyte imbalance, metabolic disorder, intoxication or trauma". Most FS occur between six months to six years ${ }^{2}$ and the median age of onset is considered as 18 months $^{3}$. The prevalence and incidence of FS depend on the geographical and cultural variations and is between $3-8 \%$ in children up to 7 years of age in the USA and Western Europe ${ }^{4,5}$. However, FS are more prevalent among the South Asian population with $9 \%$ reported in Japan and $14 \%$ in India ${ }^{2,6}$. FS are divided as simple and complex. Seventy percent experienced the simple type. The balance $30 \%$ made up the complex FS group which includes 5\% of those who go on to get febrile status epilepticus. Thirty percent of children with FS will have recurrences during their childhood and that is more prevalent between 12-24 months of age ${ }^{7}$. Family history of first degree relative with FS, onset before 18 months, a lower temperature close to $37^{\circ} \mathrm{C}$ in first seizure, and shorter duration $(<1$ hour) of the febrile period before the seizure are identified as risk factors for having subsequent FS episodes ${ }^{4,8,9}$.

The first experience of a FS in their child is a very difficult experience for all parents ${ }^{10}$. They are 
frightened and fear death or the risk of choking in their child. When these recur, parents tend to worry of injury to the child, brain damage, and epilepsy despite the natural course of FS being benign with an age-dependent loss of expression ${ }^{11}$. There are only a few studies in the literature that described parental concerns towards FS and none of them are from Sri Lanka. It is important to assess their responses since parental behaviours are often bound by cultural norms and beliefs. Since the initial management is always by the parents, it is important to assess their knowledge and readiness to face the recurrence with confidence.

\section{Objectives}

To describe the common parental responses when their child suffers from FS and also important initial first aid measures parents are aware of and able to put into practice.

\section{Method}

This is a prospective cohort study conducted at the Lady Ridgeway Children's Hospital from 2016-17. This is the second largest Children's Hospital in South East Asia with a bed strength of over 900. According to hospital statistics, an average of 6 patients with FS are admitted to each admitting ward per week. Children between the ages of 6 to 72 months, who have been admitted to the hospital following a FS (first episode or a recurrence) were included in the study. Every third admission was invited to participate in the study. All children were confirmed of having a diagnosis of FS in the absence of any features of central nervous system infection or underlying secondary metabolic derangement. Absence of the previous history of afebrile seizure/s and exclusion of possible epileptic seizures being precipitated by fever were ascertained before recruitment. Children with other epileptic seizures having concomitant FS were also excluded.

The study sample was calculated using the formula by Lwanga and Lameshow ${ }^{12}$ based on the previous study done on children with FS at the same hospital $^{13}$. Two study instruments were used. The parental responsiveness during a FS was assessed using a previously validated questionnaire ${ }^{8}$. This questionnaire was generated following several focus group discussions with parents of children who have had FS. A total of 9 parents were interviewed until the saturation point was reached. This questionnaire was then pretested amongst 20 parents for face validity and ratified with the subject expert for content validity. Time taken for completion was approximately 10 minutes. The second component checked the parental awareness/preparedness for the management of potential next convulsion in the child. This list of 12 questions included both correct and incorrect responses. Each item was scored differently, on a value determined by the experts if appropriately answered and the total score was categorized as adequate or inadequate knowledge for managing the next seizure based on the cut off value (71.43) determined by the expert panel.

Statistical analysis: Data were entered into a predesigned sheet in the Statistical Package for Software Sciences (SPSS) version 22. Frequency distributions were used to summarize categorical data. For normally distributed variables, the analysis was done using parametric tests (independent t-test for difference between means, z-test for difference between proportions). For noncategorical data, the non-parametric analysis was done and summarized by medians and interquartile ranges. Associations were described using the Chi-Square test.

Ethical issues: Ethical clearance for the research was obtained from the Ethics Review Committee of the Faculty of Medicine, University of Colombo (ERC No. EC/13/157). Written informed consent was obtained from the parents of the children participating in the study

\section{Results}

One hundred and sixty randomly selected consenting parents of children admitted to Lady Ridgeway Hospital with FS were recruited. The mean age of affected children was 2.2 years (SD 1.50). The male: female ratio was 1.53:1. A majority of them (58\%) were admitted following their child's first-ever FS. The balance $42 \%$ comprised $21.3 \%$ with $1^{\text {st }}$ recurrence, $12.5 \%$ with 2 recurrences and $8.1 \%$ with more than 2 recurrences. The type of FS was simple in 121 $(75.6 \%)$ and complex in 39 (24.4\%). Only 45 $(28 \%)$ had ongoing seizure activity at the time of admission.

Parental ages ranged from 20 to 58 years with a mean of 32.1 years (SD 6.11). Seventy six (47.5\%) of them had an educational level compatible with completing Ordinary Level standard, 59 (36.9\%) had studied up to Advanced level and 17 (10.6\%) had tertiary education. In our database, there were 149 (93.1\%) mothers, $4(2.5 \%)$ fathers, and 7 $(4.4 \%)$ others who had taken care of the child while having the FS. One hundred and fourteen (71.3\%) were unemployed comprising $109 \quad(68.1 \%)$ housewives and 5 (3.1\%) others whilst 46 (28.7\%) were employed. A family history of FS was the commonest risk factor $(33.8 \%)$, and $12.5 \%$ were found to have iron-deficiency anaemia. As mentioned earlier, out of the total population, $42 \%$ had recurrences and out of them, $6 \%$ were using some form of prophylactic medications such as oral diazepam or other anti-epileptic medications. 
The commonest parental response when the FS occurred was becoming frightened as reported by $144(90 \%)$. Other negative responses during the seizure were being confused about what to do in 76 $(47.5 \%)$ and attempting to open the mouth by force in $37(23.1 \%)$. The positive responses described by parents at the time of seizure included attempting to keep the child in a safe position by $76(47.5 \%)$, shouting for help by $114(71.25 \%)$, and feeling empowered to manage the seizure appropriately by $66(41.25 \%)$. During the analysis, it was demonstrated that becoming frightened $(p=0.005)$ and becoming confused $(p=0.001)$ were associated with experiencing the FS for the first time. In contrast, parents with past experience of a FS more than once were more empowered in managing the current seizure. $(p=0.001)$ (Table 1$)$.

However, there was no association between the past experiences of FS in the parent on the improvement of knowledge they gained during the hospital stay to act on the next event of a seizure. $(\mathrm{p}=0.092)$ (Table 2)

The knowledge of how to manage the next seizure after receiving advice following the admission to the hospital was assessed using a checklist of twelve items described in Table 3.

Table 1: Association between prior experience of febrile seizures and parental responses during the seizures

\begin{tabular}{|c|c|c|c|c|c|}
\hline Response & $\begin{array}{l}\text { Agree } \\
\text { n (\%) }\end{array}$ & $\begin{array}{c}\text { Disagree } \\
\text { n }(\%)\end{array}$ & $\begin{array}{c}\text { Don't know } \\
\text { n (\%) }\end{array}$ & $\begin{array}{l}\text { Total } \\
\text { n (\%) }\end{array}$ & p-value \\
\hline $\begin{array}{l}\text { Becoming frightened } \\
\text { First episode } \\
\text { Recurrences }\end{array}$ & $\begin{array}{l}89(55.6) \\
55(34.4)\end{array}$ & $\begin{array}{l}04(02.5) \\
12(07.5)\end{array}$ & $\begin{array}{l}0 \\
0\end{array}$ & $160(100)$ & 0.005 \\
\hline $\begin{array}{l}\text { Becoming confused } \\
\text { First episode } \\
\text { Recurrences }\end{array}$ & $\begin{array}{l}58(36.3) \\
18(11.3) \\
\end{array}$ & $\begin{array}{l}32(20.0) \\
48(30.0)\end{array}$ & $\begin{array}{c}03(01.9) \\
01(0.6)\end{array}$ & $160(100)$ & 0.001 \\
\hline $\begin{array}{l}\text { Opening mouth forcefully } \\
\text { First episode } \\
\text { Recurrences }\end{array}$ & $\begin{array}{l}26(16.3) \\
11(06.9) \\
\end{array}$ & $\begin{array}{l}67(41.9) \\
55(34.4) \\
\end{array}$ & $\begin{array}{c}0 \\
01(0.6) \\
\end{array}$ & $160(100)$ & 0.13 \\
\hline $\begin{array}{l}\text { Putting to a safe posture } \\
\text { First episode } \\
\text { Recurrences }\end{array}$ & $\begin{array}{l}33(20.6) \\
43(26.9) \\
\end{array}$ & $\begin{array}{l}59(36.9) \\
21(13.1) \\
\end{array}$ & $\begin{array}{c}01(0.6) \\
03(01.9) \\
\end{array}$ & $160(100)$ & 0.001 \\
\hline $\begin{array}{l}\text { Shouting for help } \\
\text { First episode } \\
\text { Recurrences }\end{array}$ & $\begin{array}{l}75(47.2) \\
39(24.5) \\
\end{array}$ & $\begin{array}{l}18(11.3) \\
27(17.0) \\
\end{array}$ & $\begin{array}{l}0 \\
0 \\
\end{array}$ & $160(100)$ & 0.003 \\
\hline $\begin{array}{l}\text { Feeling empowered to manage the next seizure } \\
\text { First episode } \\
\text { Recurrences }\end{array}$ & $\begin{array}{l}18(11.5) \\
48(30.6) \\
\end{array}$ & $\begin{array}{l}72(45.9) \\
15(09.6)\end{array}$ & $\begin{array}{l}02(01.3) \\
02(01.3)\end{array}$ & $160(100)$ & 0.001 \\
\hline
\end{tabular}

Table 2: Association between past experience of febrile seizures in the parent and knowledge gained during the hospital stay to manage the seizure

\begin{tabular}{|l|l|c|c|c|}
\hline \multicolumn{2}{|c|}{ Episodes } & \multicolumn{2}{c|}{ Knowledge of management during a seizure } & \multirow{2}{*}{ Total } \\
\cline { 3 - 5 } \multicolumn{2}{|l|}{} & Adequate & Inadequate & \\
\hline First Episode & Count (\%) & $16(10.0)$ & $77(48.1)$ & $93(58.1)$ \\
\hline Recurrences & Count (\%) & $19(11.9)$ & $48(30.0)$ & $67(41.9)$ \\
\hline Total & Count (\%) & $35(21.9)$ & $125(78.1)$ & $160(100.0)$ \\
\hline
\end{tabular}

Table 3: Parental response during next the seizure after being advised during the admission

\begin{tabular}{|l|c|c|c|}
\hline \multicolumn{1}{|c|}{ Action during the seizure } & $\begin{array}{c}\text { Agree } \\
\mathbf{n}(\mathbf{\%})\end{array}$ & $\begin{array}{c}\text { Disagree } \\
\mathbf{n}(\mathbf{\%})\end{array}$ & $\begin{array}{c}\text { Don't know } \\
\text { n (\%) }\end{array}$ \\
\hline Turn the child in his/her side & $134(83.8)$ & $06(03.8)$ & $20(12.5)$ \\
\hline Protect the child on a soft and safe surface & $99(61.9)$ & $24(15)$ & $37(23.1)$ \\
\hline Keep the child away from sharp and solid items & $121(75.6)$ & $08(05)$ & $31(19.4)$ \\
\hline Suck discharges from the child's nose and mouth & $97(60.6)$ & $24(15)$ & $38(23.8)$ \\
\hline Do not panic & $125(78.1)$ & $33(20.6)$ & $02(01.3)$ \\
\hline Observe the child's seizure carefully & $139(86.9)$ & $13(08.1)$ & $08(05)$ \\
\hline Do not put anything in his/ her mouth & $18(11.3)$ & $131(81.9)$ & $11(06.9)$ \\
\hline Do not restrain the convulsing child & $35(21.9)$ & $102(63.7)$ & $23(14.4)$ \\
\hline Insert Diazepam suppository if the seizure is prolonged & $10(06.3)$ & $68(42.5)$ & $79(49.4)$ \\
\hline Try to lower the child's body temperature & $122(76.3)$ & $33(20.6)$ & $03(01.9)$ \\
\hline Bring to the hospital immediately if fit doesn't resolve in 5 minutes & $102(63.7)$ & $18(11.3)$ & $40(25)$ \\
\hline If seizure settles at home, visit a doctor when the child recovers & $107(66.9)$ & $34(21.3)$ & $19(11.9)$ \\
\hline
\end{tabular}


According to that, more than a satisfactory score of 71.43, which was determined by the expert's panel, was achieved only by $35(21.9 \%)$. The mean knowledge score for managing the next seizure was 58.3 ( $\mathrm{SD}=16.8)$. Most frequent inappropriate actions performed included too frequent sponging by $122(76.3 \%)$, restraining the clonic movements by $102(63.7 \%)$ and inserting an object to mouth by $131(81.9 \%)$. According to our analysis, we could not identify a relationship between the adequacy of knowledge with the educational level of the parent (educated up to $\mathrm{O} / \mathrm{L}, \mathrm{A} / \mathrm{L}$ or higher education) or the preparedness for next seizure by the parents $(p=$ 0.826 )

\section{Discussion}

This prospective study aimed to describe the parental response during a FS and parent's knowledge on preparedness for the subsequent episodes of FS in their child among a sub-group of parents admitted to Lady Ridgeway Hospital. It was shown that the majority of parents are fearful of the experience and carry out inappropriate actions during their encounter. However, this readiness was better in parents who have experienced more than one FS.

Although FS are a familiar experience to health care workers, witnessing a child having a convulsion, for an uninformed and unsuspecting parent would be a nightmare and a frightening experience $^{14}$. As FS is the commonest cause of seizures in childhood and considering the geographically increased likelihood of FS among the South Asian population ${ }^{6}$, it is a frequent cause of fear and anxiety amongst Sri Lankan parents. The unwarranted fear and excitement during a seizure is often the reason for inappropriate management in their home settings.

Previous studies, mainly from the West, have identified that parents experienced fear and anxiety when their children developed FS, and it is more intense during the first FS episode ${ }^{15,16}$. A large proportion had considered the scenario as an impending life-threatening situation ${ }^{15}$. It has been shown that this fear is related to poor understanding and knowledge of $\mathrm{FS}^{17,18,19}$. The above findings were similarly noted in our study. However, the proportions with fear in ours were comparatively higher. At the same time, we observed that positive responses, such as shouting for help was observed in a reasonable proportion of parents experiencing the first episode.

According to other studies, the inappropriate actions by parents during a seizure include putting the child in tepid water, shaking and attempting to arouse the convulsing child, restraining the convulsing movements, opening the child's mouth with force and inserting objects into the mouth, sucking discharge from nose and mouth, administering paracetamol, hugging the child, blowing air into the child's mouth, attempting to do mouth-to-mouth resuscitation, cardiac massage and rubbing alcohol on to the child's sole ${ }^{14,20}$.

The literature on parental first-aid measures during the first $\mathrm{FS}^{16,21}$ shows that the parents' management of subsequent FS improved and was more appropriate during subsequent seizures ${ }^{20}$. The study by Huang MC et $a l^{20}$ (1998) attributed it to structured teaching on proper management of FS delivered through an educational programme done during the hospital stay at eight major referral hospitals and three outpatient clinics located in southern Taiwan. However, in the 2002 study, they found about $80 \%$ of parents anticipated rushing the child to the hospital without any first aid, $44 \%$ of parents attempted to pry the mouth open and $33 \%$ lowered the temperature of the child when the next seizure occurred, even though they had experienced FS and received medical therapy for it on previous occasions $^{22}$. In the study by Kolahi AA, et al ${ }^{14} 68 \%$ of the mothers during seizure episodes, had brought their child to the hospital without performing any first-aid measures. Our findings also showed a mixed response with some inappropriate responses such as remaining confused, attempting to open the mouth and at the same time, positive responses were seen such as putting to a safe posture, shouting for help, and feeling empowered to manage the seizure appropriately.

It has been shown that familial cultural and ethnic background independently influenced the parental misconceptions and practices regarding fever and subsequent FS management in children ${ }^{23}$. The most common concerns among the parents were the state of their child's health in the future, fear of recurrence, mental retardation, paralysis or physical disability, and learning dysfunction. The same study has stated that parents with higher educational levels are well aware of the preventive measures to face the recurrence ${ }^{14}$. However, our findings did not demonstrate this relationship between the level of education and the preparedness for the next seizure of the parents.

First aid during FS or epilepsy is to protect the individual from incurring harm during a seizure. Many parents or guardians have misconceptions about seizures or poor understanding of how to respond to a seizure. Guidelines for first aid during a seizure from the Epilepsy Foundation ${ }^{24}$, and other Epilepsy care websites provide a better understanding of first aid management. Presently only a poor improvement was achieved after seizure first aid education given in hospitals ${ }^{24}$. Admitting doctors, paediatricians, paediatric 
trainees, nurses and other health staff will need to be trained on parent education. A pre-identified protocol will help to deliver a comprehensive and uniform message to the parents.

\section{Conclusions}

This study revealed both negative and positive parental responses when their child experienced a febrile seizure. These responses led them to perform inappropriate first aid measures.

\section{Acknowledgements}

We thank the parents who participated in the focused group discussion and also participated in the pilot study. We also thank the many research assistants who have helped in their capacities towards the conduct of the study.

\section{References}

1. Guidelines for epidemiologic studies on epilepsy. Commission on epidemiology and prognosis, international league against epilepsy. Epilepsia 1993; 34(4):592-6. https://doi.org/10.1111/j.15281157.1993.t b00433.x

PMid: 8330566

2. American Academy of Pediatrics. Practice parameter: long-term treatment of the child with simple febrile seizures. American Academy of Pediatrics. Committee on Quality Improvement, Subcommittee on Febrile Seizures. Pediatrics 1999; 103(6):1307-9. https://doi.org/10.1542/peds.103.6.1307 PMid: 10353950

3. Offringa M, Bossuyt PM, Lubsen J, Ellenberg JH, Nelson KB, Knudsen FU, et al. Risk factors for seizure recurrence in children with febrile seizures: a pooled analysis of individual patient data from five studies. The Journal of Pediatrics 1994; 124(4): 574-84. https://doi.org/10.1016/S00223476(05)83 136-1

4. Sadleir LG, Scheffer IE. Febrile seizures. British Medical Journal 2007; 334(7588): 307-11.

https://doi.org/10.1136/bmj.39087.691817 .AE

PMid: 17289734 PMCid: PMC1796669

5. Shinnar S. Febrile seizures and mesial temporal sclerosis. Epilepsy Currents 2003; 3(4):115-8. https://doi.org/10.1046/j.15357597.2003.0

3401.x

PMid: 15309049 PMCid: PMC321192

6. Canpolat M, Per H, Gumus H, Elmali F, Kumandas S. Investigating the prevalence of febrile convulsion in Kayseri, Turkey: An assessment of the risk factors for recurrence of febrile convulsion and for development of epilepsy. Seizure 2018; 55: 36-47.

https://doi.org/10.1016/j.seizure.2018.01.0 07

PMid: 29353090

7. Offringa M, Newton R, Cozijnsen MA, Nevitt SJ. Prophylactic drug management for febrile seizures in children. Cochrane Database of Systematic Reviews 2017; 2: CD003031

https://doi.org/10.1002/14651858.CD0030 31.pub3

PMCid: PMC6464693

8. Berg AT, Shinnar S, Darefsky AS, Holford TR, Shapiro ED, Salomon ME, et al. Predictors of recurrent febrile seizures: a prospective cohort study. Archives of Pediatrics \& Adolescent Medicine 1997; 151(4):371-8.

https://doi.org/10.1001/archpedi.1997.021

70410045006

PMid: 9111436

9. Shinnar S, Glauser T. Febrile seizures. Journal of Child Neurology 2002; 17(suppl.): S44-S52.

https://doi.org/10.1177/088307380201700 10601

PMid: 11918463

10. Sajadi M, Khosravi S. Mothers' experiences about febrile convulsions in their children: a qualitative study. International Journal of Community based Nursing and Midwifery 2017; 5(3):284.

11. Freeman J. The best medicine for febrile seizures. New England Journal of Medicine 1992; 327(16): 1161-3. https://doi.org/10.1056/NEJM1992101532 71610

PMid: 1528213

12. Lemeshow S, Hosmer DW, Klar J, Lwanga SK, World Health Organization. Adequacy of sample size in health studies. Chichester: Wiley; 1990. 
13. Liyanage G, De Silva TU, Perera BJ. A survey on febrile seizures at the Lady Ridgeway Hospital for Children. Sri Lanka Journal of Child Health 2005; 34(4): 109-13.

https://doi.org/10.4038/sljch.v34i4.389

14. Kolahi AA, Tahmooreszadeh S. First febrile convulsions: inquiry about the knowledge, attitudes and concerns of the patients' mothers. European Journal of Pediatrics 2009; 168(2):167. https://doi.org/10.1007/s00431-008-0724Z

PMid: 18461360

15. Baumer JH, David TJ, Valentine SJ, Roberts JE, Hughes BR. Many parents think their child is dying when having a first febrile convulsion. Developmental Medicine \& Child Neurology 1981; 23(5):462-4.

https://doi.org/10.1111/j.14698749.1981.t b02019.x

PMid: 7274593

16. Balslev T. Parental reactions to a child's first febrile convulsion: A follow-up investigation. Acta Pcediatrica 1991; 80(4): 466-9.

https://doi.org/10.1111/j.16512227.1991.t b11883.x

PMid: 2058397

17. Kanemura H, Sano F, Mizorogi S, Tando T, Sugita K, Aihara M. Parental thoughts and actions regarding their child's first febrile seizure. Pediatrics International 2013; 55(3):315-9.

https://doi.org/10.1111/ped.12058

PMid: 23360347

18. Stuijvenberg MV, Vos SD, Tjiang GC, Steyerberg EW, Derksen-Lubsen G, Moll HA. Parents' fear regarding fever and febrile seizures. Acta Paediatrica 1999; 88(6): $618-22$. https://doi.org/10.1111/j.16512227.1999.b 00010.x

PMid: 10419245

19. Wirrell E, Turner T. Parental anxiety and family disruption following a first febrile seizure in childhood. Paediatrics \& Child Health 2001; 6(3):139-43.

https://doi.org/10.1093/pch/6.3.139

PMid: 20084226 PMCid: PMC2804529

20. Huang MC, Liu CC, Huang CC. Effects of an educational program on parents with febrile convulsive children. Pediatric Neurology 1998; 18(2):150-5. https://doi.org/10.1016/S08878994(97)00 171-9

21. Rutter N, Metcalfe DH. Febrile convulsions--what do parents do? British Medical Journal 1978; 2(6148):1345-6. https://doi.org/10.1136/bmj.2.6148.1345 PMid: 719385 PMCid: PMC1608426

22. Huang MC, Liu CC, Huang CC, Thomas $\mathrm{K}$. Parental responses to first and recurrent febrile convulsions. Acta Neurologica Scandinavica 2002; 105(4):293-9. https://doi.org/10.1034/j.16000404.2002.1 o200.x

PMid: 11939942

23. Tessler H, Gorodischer R, Press J, Bilenko $\mathrm{N}$. Unrealistic concerns about fever in children: the influence of cultural-ethnic and sociodemographic factors. The Israel Medical Association Journal 2008; 10(5): 346.

24. O'Hara KA. First aid for seizures: the importance of education and appropriate response. Journal of Child Neurology 2007; 22(5_suppl): 30S-7S. https://doi.org/10.1177/088307380730306 6

PMid: 17690085 